\title{
Why Is the Mediterranean a Climate Change Hot Spot? 0
}

\author{
A. Tuel and E. A. B. Eltahir \\ Ralph M. Parsons Laboratory, Massachusetts Institute of Technology, Cambridge, Massachusetts
}

(Manuscript received 5 December 2019, in final form 20 April 2020)

\begin{abstract}
Higher precipitation is expected over most of the world's continents under climate change, except for a few specific regions where models project robust declines. Among these, the Mediterranean stands out as a result of the magnitude and significance of its winter precipitation decline. Locally, up to $40 \%$ of winter precipitation could be lost, setting strong limits on water resources that will constrain the ability of the region to develop and grow food, affecting millions of already water-stressed people and threatening the stability of this tense and complex area. To this day, however, a theory explaining the special nature of this region as a climate change hot spot is still lacking. Regional circulation changes, dominated by the development of a strong anomalous ridge, are thought to drive the winter precipitation decline, but their origins and potential contributions to regional hydroclimate change remain elusive. Here, we show how wintertime Mediterranean circulation trends can be seen as the combined response to two independent forcings: robust changes in largescale, upper-tropospheric flow and the reduction in the regional land-sea temperature gradient that is characteristic of this region. In addition, we discuss how the circulation change can account for the magnitude and spatial structure of the drying. Our findings pave the way for better understanding and improved modeling of the future Mediterranean hydroclimate.
\end{abstract}

\section{Introduction}

Located at the border between the arid subtropics and the temperate midlatitudes, the Mediterranean Basin is characterized by low annual precipitation totals and high interannual variability, which impose a state of semipermanent water stress across much of North Africa and the Middle East. Summers are warm and dry, dominated to the east by the influence of subtropical remote forcing triggered by the Indian monsoon, which causes intense subsidence across the region (Rodwell and Hoskins 1996), and to the west by the subtropical high. In winter, however, the Mediterranean Sea region is largely outside the influence of such tropical teleconnections, and storms and rain are brought by midlatitude westerlies. Consequently, winter precipitation is key to the region's agriculture and economy, with its future of paramount importance for the basin's countries. Regional- and local-scale processes, such as

\footnotetext{
Supplemental information related to this paper is available at the Journals Online website: https://doi.org/10.1175/JCLI-D-190910.s1.
}

Corresponding author: A. Tuel, atuel@mit.edu land-sea circulations, also play a significant part in shaping Mediterranean climate variability and climate change (Bolle 2003).

The Mediterranean has long stood out in successive generations of global climate models (GCMs) as being particularly sensitive to rising concentrations of greenhouse gases. Models overwhelmingly project, across all scenarios, a large reduction in precipitation, more than in other land regions in relative terms (Fig. 1b) (Giorgi and Lionello 2008; Planton et al. 2012). A large part of that decline occurs during winter, south of $40^{\circ} \mathrm{N}$ (Fig. 1d), with enhanced drying over northwestern Africa [from $-30 \%$ to $-40 \%$ in December-February (DJF) precipitation] and the eastern Mediterranean (from $-20 \%$ to $-25 \%$ ). In summer, significant warming and drying is also projected for the northern Mediterranean (Brogli et al. 2019). While the large interannual variability in wintertime Mediterranean climate makes the significance of past trends hard to establish (Kelley et al. 2012), observations and reanalysis products are in general consistent with historical simulations and projections for the upcoming century (Fig. 2b). The Mediterranean has experienced substantial drying over the last century, part of which cannot be explained by simple internal variability 
a

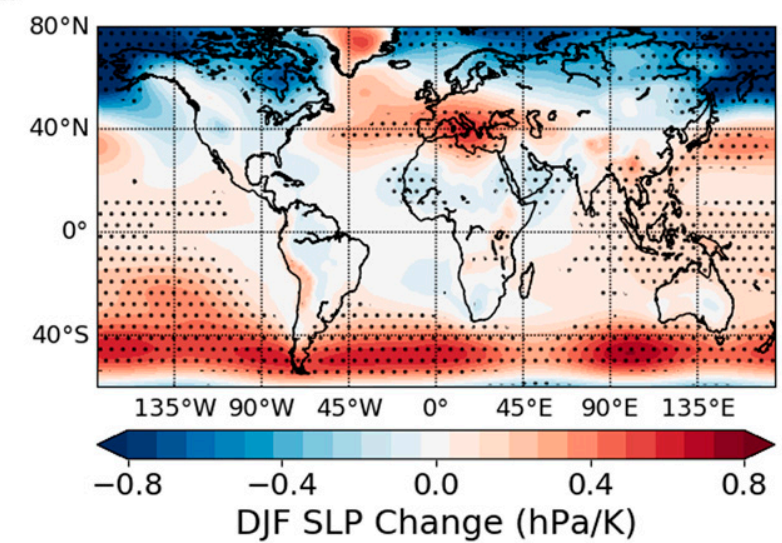

b

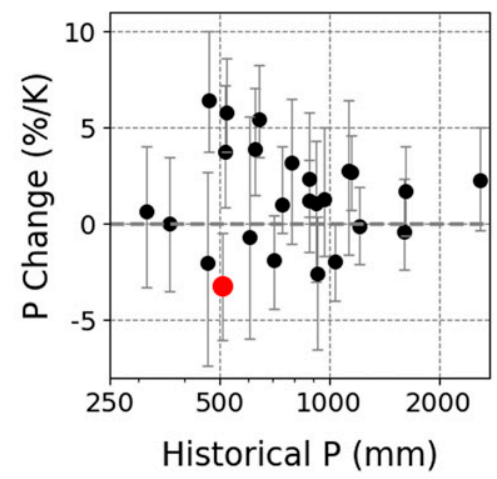

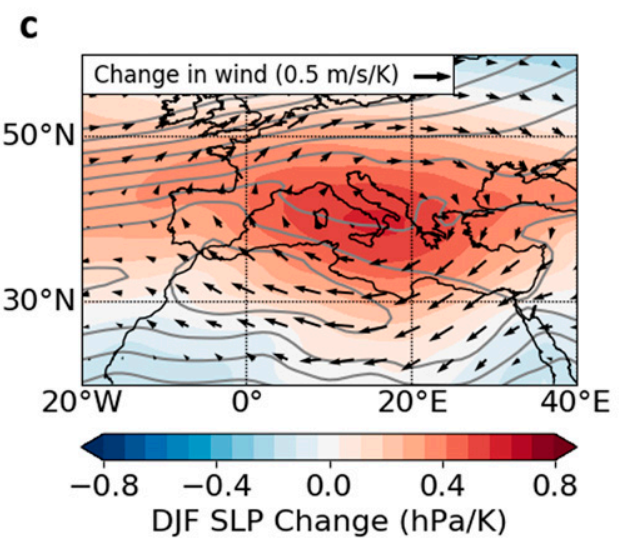

d

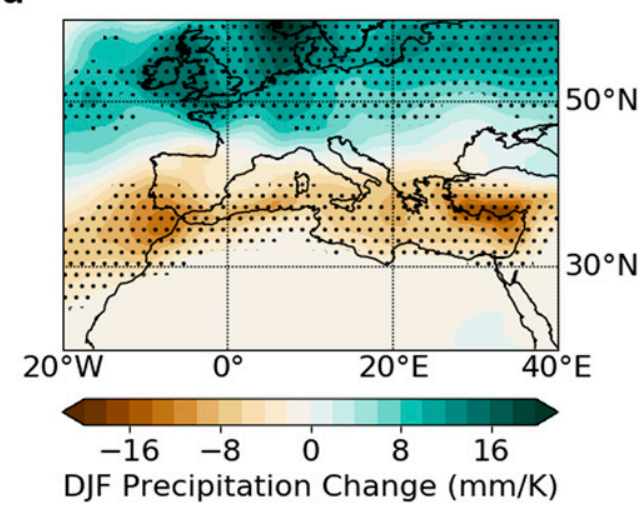

FIG. 1. CMIP5 winter (DJF) multimodel mean projected change in (a) worldwide SLP, (c) Mediterranean SLP and 850-hPa winds, and (d) Mediterranean precipitation under RCP8.5 (2071-2100 minus 1976-2005). Historical DJF SLP contours are also shown in (c) (from 1010 to $1024 \mathrm{hPa}$ every $2 \mathrm{hPa}$; the closed contour over North Africa is $1024 \mathrm{hPa}$ ). Dots in (a) and (d) indicate that more than $80 \%$ of models agree on the sign of the change. Also shown is (b) median (black dots) and $90 \%$ intermodel spread (gray whiskers) of relative change in annual precipitation in CMIP5 models under RCP8.5 (2071-2100 minus 1976-2005), against annual mean historical (1976-2005) precipitation, for 25 land regions covering the whole globe (Giorgi and Bi 2005). The Mediterranean is highlighted with a red dot. In (a)-(d), projections have been renormalized by each model's global projected temperature change.

(Hoerling et al. 2012; Kelley et al. 2012). An unprecedented drought in the eastern Mediterranean exacerbated the already tense situation in Syria that led to the outbreak of a civil war (Kelley et al. 2015). Further drying will inevitably exacerbate social and geopolitical tensions in this severely water-stressed region.

Changes in the regional low-level circulation have long been suspected to play a dominant role in the winter Mediterranean drying (e.g., Seager et al. 2014; Zappa and Shepherd 2017; Tuel and Eltahir 2018; Brogli et al. 2019), in particular through the development of an anomalous surface anticyclone over the Mediterranean Basin (Seager et al. 2019), a striking feature of global climate projections (Figs. 1a,c). This anomalous Mediterranean ridge extends from roughly November to April and has been consistently present in successive generations of models (Giorgi and Lionello 2008). Its magnitude, and that of the associated wind field, is strongly correlated to the regional precipitation decline across models (Fig. S2 in the online supplemental material) (Zappa et al. 2015b). Observed trends have up to now been consistent with model projections (Fig. 2a). Giorgi and Lionello (2008) suggested that the anomalous high may drive the projected drying by increasing atmospheric stability in the region and suppressing Mediterranean cyclones, as discussed in later studies (e.g., Rojas et al. 2013; Zappa et al. 2015a). Subsequently, based on a threedimensional analysis of the moisture budget, Seager et al. (2014) concluded that the Mediterranean precipitation decline was due to increased moisture divergence by the time-mean flow, due to anomalous anticyclonic circulation in the region. Zappa et al. (2015b) additionally showed that the intermodel spread in precipitation change could be well captured by a 
a
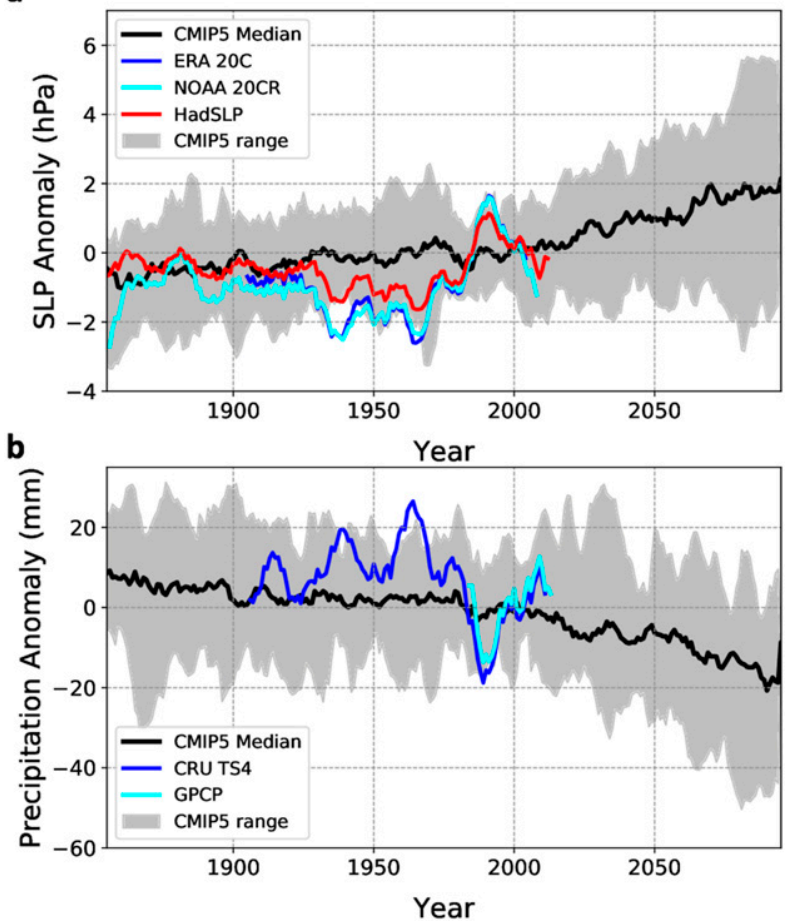

FIG. 2. Five-year smoothed median (black line) and range (gray shading) of CMIP5 model simulations of DJF Mediterranean (a) SLP $\left(0^{\circ}-30^{\circ} \mathrm{E}, 32^{\circ}-48^{\circ} \mathrm{N}\right)$ and (b) precipitation $\left(20^{\circ} \mathrm{W}-40^{\circ} \mathrm{E}\right.$, $30^{\circ}-45^{\circ} \mathrm{N}$ ) anomalies (map on Fig. S1 of the online supplemental material), alongside observations/reanalysis data from HadSLP2, NOAA 20CR, and ERA-20C [in (a)] and GPCP and CRU TS4 v2 [in (b)].

simple wind index reflective of the regional circulation, supporting the idea that future Mediterranean hydroclimate trends are primarily driven by changes in the regional atmospheric circulation (Fig. S2).

Why the anomalous high pressure develops in the first place, however, and how it connects to the robust pattern of the precipitation response remains unclear. Changes in the large-scale circulation, notably the expansion of the Hadley circulation (Lu et al. 2007) and the corresponding poleward shift of the North Atlantic storm track (Yin 2005; Scheff and Frierson 2012; Woollings et al. 2012), the weakening of the Mediterranean storm track, and changes in regional flow regimes (Zappa et al. 2015a; Rojas et al. 2013), have previously been suggested as driving mechanisms behind Mediterranean circulation trends. More recently, the role of shifts in Northern Hemisphere stationary waves was shown to modulate precipitation projections over California (Simpson et al. 2016) and suspected to impact the Mediterranean as well (Seager et al. 2019). Tuel and Eltahir (2018) also first suggested that the regional warming contrast between land and sea could play a role. Still, the specific contributions of those mechanisms to projected Mediterranean climate trends and their spread has not been clearly quantified. Additionally, the role of Hadley cell and storm-track shifts has been challenged as they were found to occur, in abrupt$\mathrm{CO}_{2}$ experiments, on a much faster time scale than the Mediterranean drying (He and Soden 2017). The zonal symmetry in Hadley cell shifts is also at odds with the amplified Mediterranean sea level pressure (SLP) signal (Fig. 1a), so that it is not obvious why the Mediterranean would be particularly sensitive in climate projections.

Therefore, while much attention has been given to this region, a comprehensive theory for the wintertime Mediterranean precipitation decline is still lacking. In this study, we seek to understand what drives projected wintertime low-level circulation and precipitation trends in the region, with winter defined as the DJF period. Based on results of simulations from phase 5 of the Coupled Model Intercomparison Project (CMIP5) and idealized simulations with the Massachusetts Institute of Technology (MIT) Regional Climate Model, we show that global-scale circulation changes originating near the tropopause and the independent response to changes in the sea-land surface temperature gradient over the Mediterranean Basin greatly contribute to future trends in the Mediterranean hydroclimate. In addition, we discuss the physical connections between circulation and precipitation projections in the western and eastern Mediterranean. Our primary focus is the CMIP5 multimodel mean, but intermodel spread is also discussed in the light of the two proposed mechanisms.

\section{Data}

We analyze recent surface temperature, pressure, and precipitation trends in the Mediterranean region using various datasets. Observed surface temperatures are taken from the NOAA Merged Land-Ocean Surface Temperature Analysis (MLOST; Vose et al. 2012) (land and ocean; 1850-2018), and the CRU TS4.02 dataset (Harris et al. 2014) (land only; 1901-2018). Monthly precipitation over land from CRU TS4.02 is also used, and, for ocean coverage, we consider data from the Global Precipitation Climatology Project, version 2.3 (Adler et al. 2003), as well (1979-2018). Sea surface temperature (SST) data are taken from HadISST (Rayner et al. 2003) and ERSST v5 (Huang et al. 2017). SLP from the HadSLP2 dataset (1850-2018) is used (Allan and Ansell 2006); for purposes of comparison, we also look at SLP in the NCEP-NCAR (Kalnay et al. 1996), NOAA 20CR (Compo et al. 2011), and ERA twentieth-century (20c; Poli et al. 2016) reanalyses.

Future climate trends are analyzed using $30 \mathrm{GCM}$ simulations from CMIP5 (Taylor et al. 2012), under the 


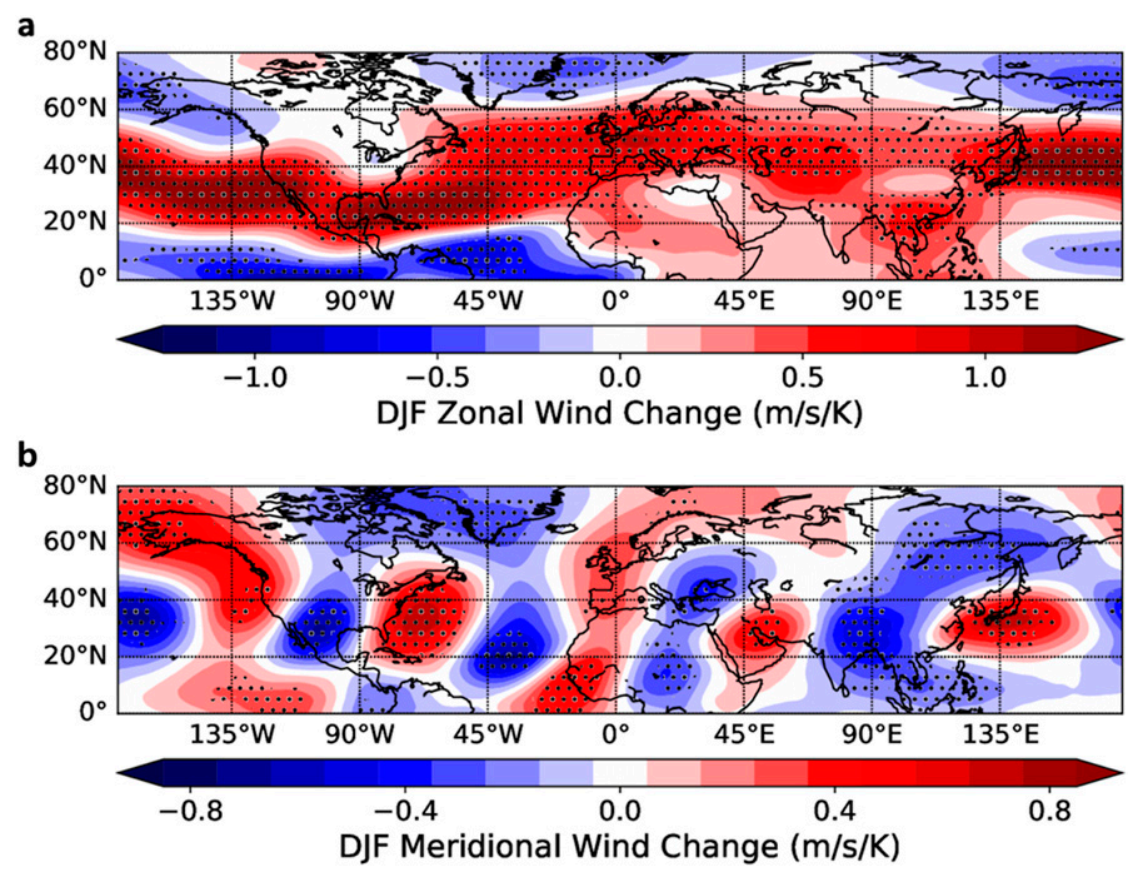

FIG. 3. CMIP5 winter (DJF) multimodel mean projected change in Northern Hemisphere $200-\mathrm{hPa}$ (a) zonal and (b) meridional winds. Dots indicate that more than $80 \%$ of models agree on the sign of the change. For each model, projections have been renormalized by that model's global projected temperature change.

historical and representative concentration pathway 8.5 (RCP8.5) scenarios. We used all models that provided SLP, precipitation, surface temperature, and specific humidity, temperature, winds, and pressure velocity on pressure levels at monthly resolution for our reference (1976-2005) and future (2071-2100) periods. A detailed list of the 30 selected models can be found in Table $\mathrm{S} 1$ in the online supplemental material (expansions of model acronyms are available at https:// www.ametsoc.org/Pubs AcronymList). For each model, only the r1i1p1 ensemble member is used. All model output is regridded to a common $1^{\circ} \times 1^{\circ}$ grid. Unless specified, all changes under RCP8.5 are defined as the 2071-2100 minus 1976-2005 average, and all anomalies (of SLP, precipitation, etc.) are defined with respect to the 1976-2005 reference period.

\section{Quantifying the SLP response to upper-level circulation change}

CMIP5 GCMs robustly agree on the pattern of Northern Hemisphere upper-tropospheric circulation change under continued anthropogenic forcing: a strengthening of the midlatitude jet (Barnes and Polvani 2013) and associated shift in the pattern of quasi-stationary waves (Brandefelt and Krnich 2008)
(Fig. 3). A direct consequence of these changes is the development of an upper-tropospheric, anomalous anticyclonic circulation over the Mediterranean. Because of the generally equivalent barotropic character of winter stationary waves (Held et al. 2002), it is expected that such a change in upper-level flow would translate into anticyclonic circulation and higher pressure at low levels.

\section{a. Methods}

To quantify the impact of trends in upper-tropospheric flow on Mediterranean low-level circulation, we apply to each selected GCM an analog-based "dynamical adjustment" model. We give here a brief overview of the method presented in Deser et al. (2016) and refer to their paper for further mathematical details. We consider two physical fields, a predictor field $\mathbf{X} \in \mathrm{R}^{p}$, and a predictand field $\mathbf{Y} \in \mathrm{R}^{q}$, linked by some physical relationship (variability in $\mathbf{X}$ influences variability in $\mathbf{Y}$ ); $p$ and $q$ refer to the space dimension. We assume that a "training" series of concurrent values of $\mathbf{X}$ and $\mathbf{Y}$, of length $n$, is available, which we note $\left(\mathbf{X}_{i}\right)_{0 \leq i \leq n}$ and $\left(\mathbf{Y}_{i}\right)_{0 \leq i \leq n}$. The goal of dynamical adjustment is to estimate the amplitude of the field $\mathbf{Y}_{t}$ associated with the predictor field $\mathbf{X}_{t}$, observed at a time $t>n$. To that end, we select the $N=50$ closest analogs of field $\mathbf{X}_{t}$ among 
the $\left(\mathbf{X}_{i}\right)_{0 \leq i \leq n}$, with Euclidean distance used as the metric. Among these $N$ fields, we randomly select a subsample of $M=30$ fields, which are assembled in a $p \times M$ matrix $\mathbf{X}_{c}$. The corresponding $\mathbf{Y}$ values are similarly put in matrix $\mathbf{Y}_{c}$. Then, optimal linear combination weights $\beta$ are estimated such that

$$
\mathbf{X}_{t} \approx \beta \mathbf{X}_{c}
$$

$\beta \mathbf{X}_{c}$ represents a "constructed analog" of $\mathbf{X}_{t}$. The same weights $\beta$ are also applied to $\mathbf{Y}_{c}$ to estimate the component of $\mathbf{Y}_{t}$ induced by predictor $\mathbf{X}_{t}: \hat{\mathbf{Y}}_{t}=\beta \mathbf{Y}_{c}$. The procedure is then repeated 1000 times, each time with a new random subsample of 30 analogs. The purpose of this subsampling is to increase robustness of the results and better quantify the variability in the reconstructed estimates (Deser et al. 2016). The results are not particularly sensitive to the specific choice of $N$ and $M$ over the range $30 \leq N \leq 60$ and $M \approx 2 N / 3$.

The method is applied to each GCM separately, using for $\mathbf{X}$ the DJF meridional wind field anomalies at $200 \mathrm{hPa}$ in the $20^{\circ}-80^{\circ} \mathrm{N}$ latitude range, and for $\mathbf{Y}$ the Northern Hemisphere DJF SLP anomaly field. Seasonal anomalies are computed by subtracting from each field its 1976-2005 mean. The historical (1850-2005) simulations are used as "training" series (thus $n=155$ winters), and we calculate constructed analogs for all winters between 2070 and 2100. Our choice of predictor is motivated by the results of Simpson et al. (2016), which implied that projected upper-level meridional wind anomalies were reflective of the shifts in mean stationary wave structure. Results are not significantly different when using the zonal wind component, or even the streamfunction, since upper-tropospheric flow is essentially nondivergent at seasonal time scales.

An important assumption of this approach is that, at first order at least, the surface circulation response to upper-level wind pattern change is linear. To test that hypothesis, we also reconstruct annual SLP anomalies in the historical runs: for each of the 155 winters in 1850 2005, the other 154 winters are used to look for analogs. This helps determine whether interannual variability of Mediterranean SLP is correctly reconstructed in both historical and future simulations.

\section{b. Results}

Most of the year-to-year variability in DJF Mediterranean SLP is well reconstructed based on upper-tropospheric flow anomalies, in both historical and RCP8.5 runs (Fig. 4c). The model-mean squared correlation coefficient is about 0.75 for each scenario (model range is $0.55-0.85$ ), and the average root-mean-square error is $1.2 \mathrm{hPa}$ (model range $0.95-1.5 \mathrm{hPa})$. SLP anomalies are correctly approximated over the whole range of interannual variability; only very low SLP values seem to be slightly overestimated. Despite the mean shift toward positive SLP anomalies in future projections, the range of values of RCP8.5 anomalies is not substantially different from historical ones. This increases our confidence that the method will correctly capture shifts in the distribution of SLP anomalies connected to projected changes in upper-level wind fields. Looking ahead, we find that future upper-tropospheric wind patterns are consistent with an amplified SLP response over the Mediterranean and also east of Japan (Figs. 4a,b). They also account for $80 \%$ of intermodel spread in Mediterranean projections (Fig. 4d). The decrease in SLP over the North Pacific is also well reproduced, but not so much over North America, the North Atlantic, and Siberia, where other factors, notably linked to thermodynamic forcing [e.g., Arctic amplification and the North Atlantic warming hole (NAWH)] likely play a role (Gervais et al. 2019). However, only $40 \%$ of the mean GCM response is accounted for $(0.7 \mathrm{hPa}$ as compared with $1.7 \mathrm{hPa}$ in the multimodel mean). In some models, this dynamically induced SLP change is even of the opposite sign of the total simulated response by that same model (Fig. 4d). Similarly, during the "extended" winter season, outside DJF, future upper-tropospheric circulation anomalies are still connected to an increase in SLP over the Mediterranean but explain only $\sim 30 \%-40 \%$ of the whole signal (Fig. S3 in the online supplemental material).

\section{Surface thermodynamical forcing}

The geography of the Mediterranean Basin is unique, characterized by the existence of a large sea enclosed by continents on almost all sides. During winter, because of water's larger thermal capacity, the Mediterranean Sea is on average warmer than the surrounding land. However, as a result of enhanced warming over land under climate change (Sutton et al. 2007; Byrne and O'Gorman 2018), future climate projections exhibit a robust and gradual relative cooling of the Mediterranean Sea with respect to surrounding land (Fig. 5a). We define a simple sea-land temperature difference index as the difference between mean DJF temperatures over sea and over land in the Mediterranean region $\left(5^{\circ} \mathrm{W}-38^{\circ} \mathrm{E}, 28^{\circ}-48^{\circ} \mathrm{N}\right.$; Fig. 5a). In historical CMIP5 simulations and ERA-Interim, that difference reaches about $5^{\circ} \mathrm{C}$; by $2100, \mathrm{RCP} 8.5$ simulations project a $0.5^{\circ} \mathrm{C}$ decrease, with little spread across models (Fig. 5b). The magnitude of the projected index change is similar to its historical interannual standard deviation, suggesting a potentially important role of sea-land temperature change in shaping future regional circulation. Up to now, 
a

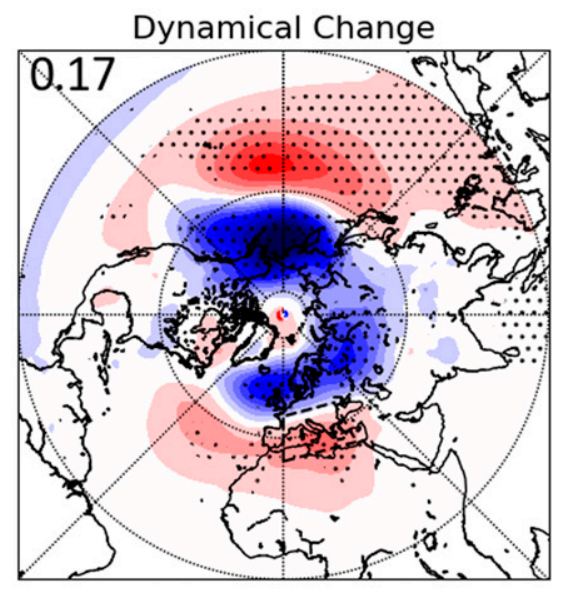

b

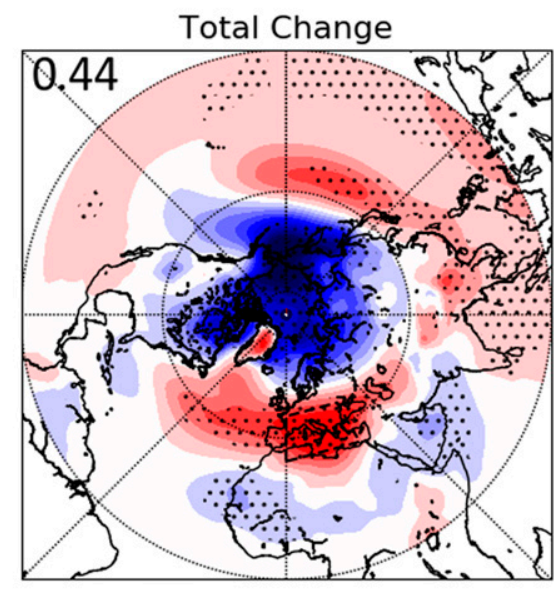

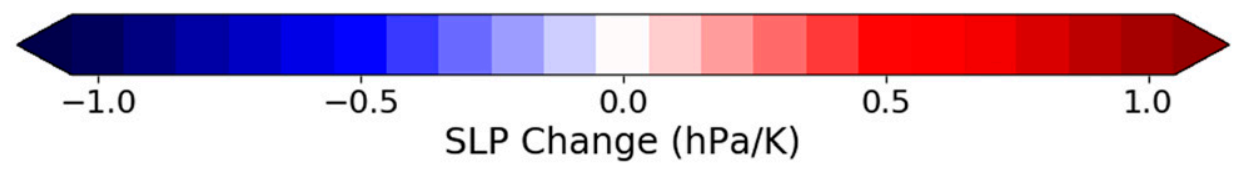

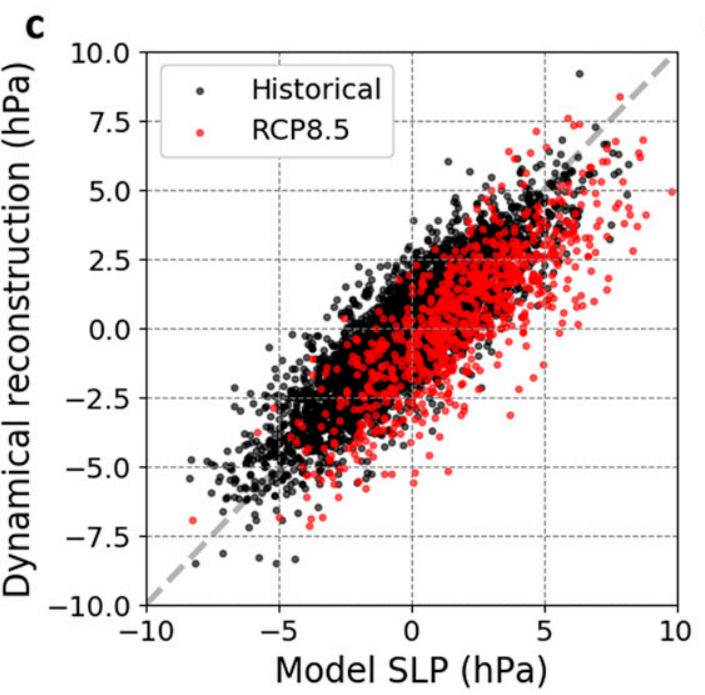

d

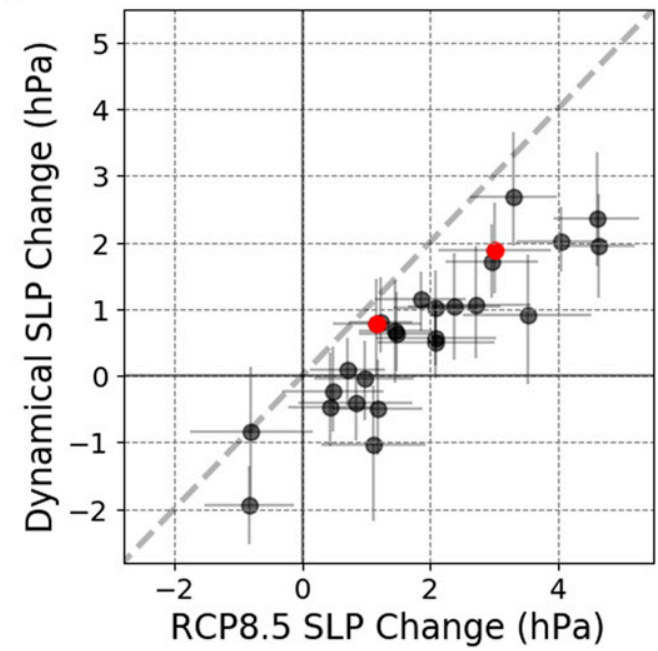

FIG. 4. Northern Hemisphere CMIP5 multimodel mean change in DJF SLP (a) estimated by dynamical adjustment and (b) projected by CMIP5 models. Stippling shows agreement on the sign of the change by $80 \%$ of models. Numbers indicate average value within the dash-outlined box. (c) Model vs dynamically reconstructed DJF Mediterranean $\left(0^{\circ}-30^{\circ} \mathrm{E}, 32^{\circ}-48^{\circ} \mathrm{N}\right) \mathrm{SLP}$ anomalies in historical (black dots) and RCP8.5 (red dots) simulations, for all 30 CMIP5 models. (d) Mediterranean $\left(0^{\circ}-30^{\circ} \mathrm{E}, 32^{\circ}-48^{\circ} \mathrm{N}\right)$ CMIP5 intermodel change in DJF SLP estimated by the dynamical adjustment model along with $90 \%$ confidence intervals. The two models used in Brogli et al. (2019) are highlighted with red dots.

the projected decrease has been consistent with a range of observational datasets (Fig. 5c). The impact of surface SST anomalies on regional circulations has been investigated, both from a theoretical perspective (Hoskins and Karoly 1981) and in model projections for the coming century (e.g., Gervais et al. 2019). At leading order, using geostrophic balance, a shallow relative cooling over the Mediterranean should result in anomalous surface anticyclonic circulation, since the land-sea warming contrast disappears in the midtroposphere (Byrne and O'Gorman 2016). Linear theory similarly suggests a baroclinic response to a Mediterranean negative SST anomaly characterized by a downstream SLP high (Hoskins and Karoly 
a

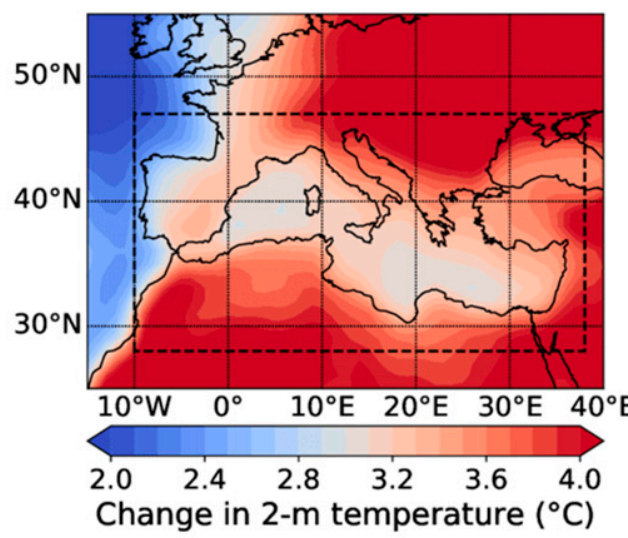

b

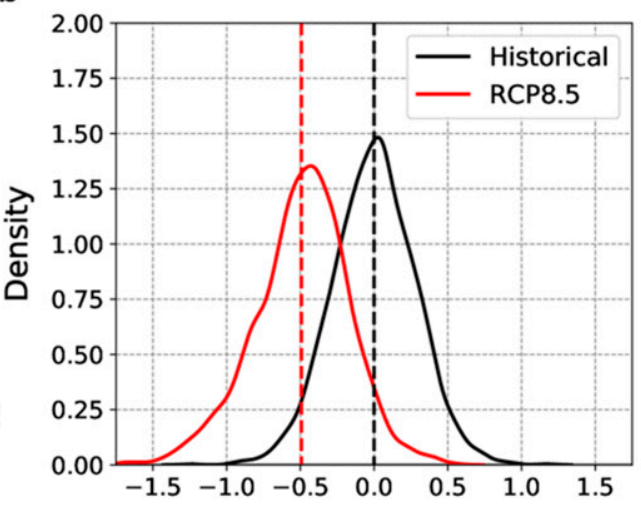

Sea-Land Temperature Diff. Anomaly $\left({ }^{\circ} \mathrm{C}\right)$

C

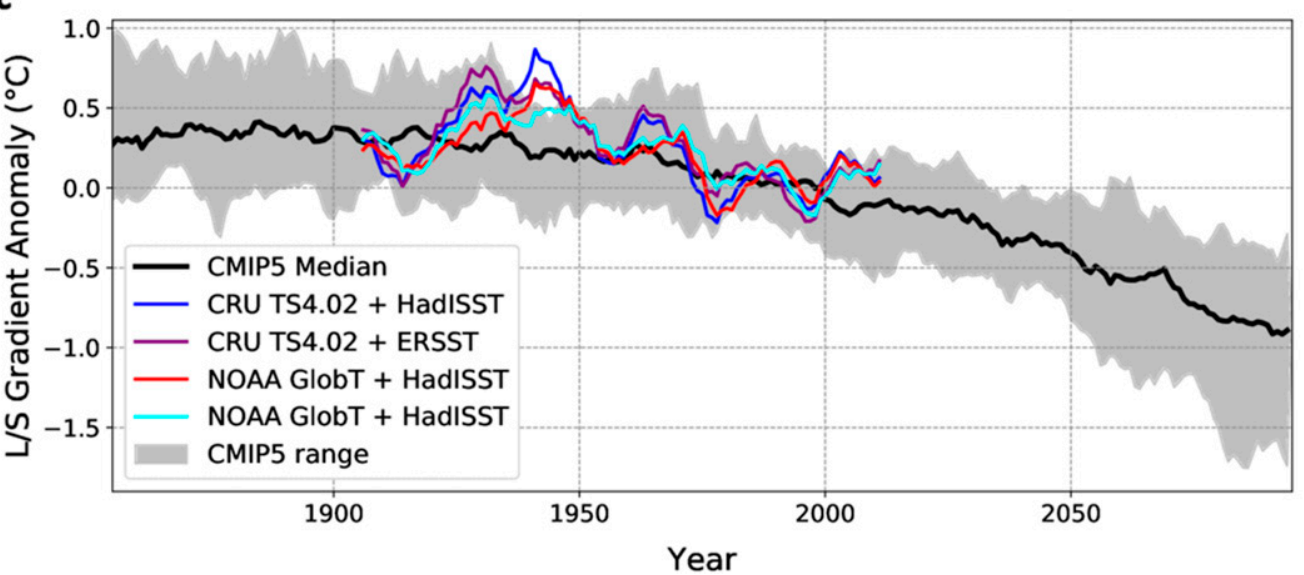

FIG. 5. (a) CMIP5 multimodel DJF 2-m temperature change under RCP8.5 (2071-2100 minus 1976-2100). The dash-outlined box encompasses the area used to calculate the sea-land temperature index. (b) Distribution of historical (black) and RCP8.5 (red) DJF sea-land temperature index anomalies across CMIP5 models. (c) Fiveyear smoothed median value (black line) and range (gray shading) of CMIP5 model annual values (1850-2095) of DJF sea-land temperature index anomalies, alongside observations from CRU, NOAA Global Surface Temperature, ERSST, and HadISST. In (c) only, the temperature index is defined using SST over the sea and not 2-m temperature, since the latter has limited availability over sea areas in observations.

1981). A similar result has been obtained while investigating the atmospheric response to the relative cooling of the NAWH in a realistic model (Gervais et al. 2019).

\section{a. Model simulations}

We investigate the impact of the land-sea warming contrast on Mediterranean circulation using regional climate simulations with the MIT Regional Climate Model (MRCM). MRCM is based on the Abdus Salam International Centre for Theoretical Physics Regional Climate Model, version 3 (RegCM3) (Pal et al. 2007), and includes several improvements (Winter et al. 2009; Gianotti et al. 2012; Gianotti and Eltahir 2014a,b) achieved through incorporation of new physical schemes or modification of original schemes. MRCM has been rigorously tested against observations in its ability to simulate key observed climate features across several regions [e.g., North America (Winter et al. 2009), West Africa (Im and Eltahir 2018b), the "Maritime Continent" (Im and Eltahir 2018a), and southwestern Asia (Pal and Eltahir 2016)].

We conduct two sets of simulations to assess the impact of the Mediterranean relative cooling over a domain that encompasses the whole Mediterranean and Black Seas (Fig. 6), at a horizontal resolution of $35 \mathrm{~km}$ and using 40 vertical levels. The first set is driven by the $1.5^{\circ} \times 1.5^{\circ}$ 6-hourly ERA-Interim reanalysis (Dee et al. 2011 ) as lateral boundary conditions and $1^{\circ} \times 1^{\circ}$ weekly NOAA OISST v2 (Reynolds et al. 2007) for the ocean surface, over the 1981-2011 period. In the second, we use the MPI-ESM-MR model (Zanchettin et al. 2013) under the RCP8.5 scenario as boundary conditions, over the 2070-2100 period. The MPI experiments are intended 
a

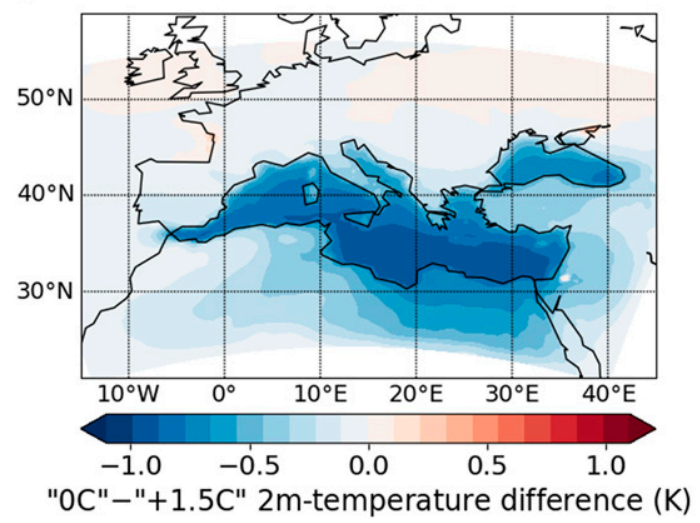

b

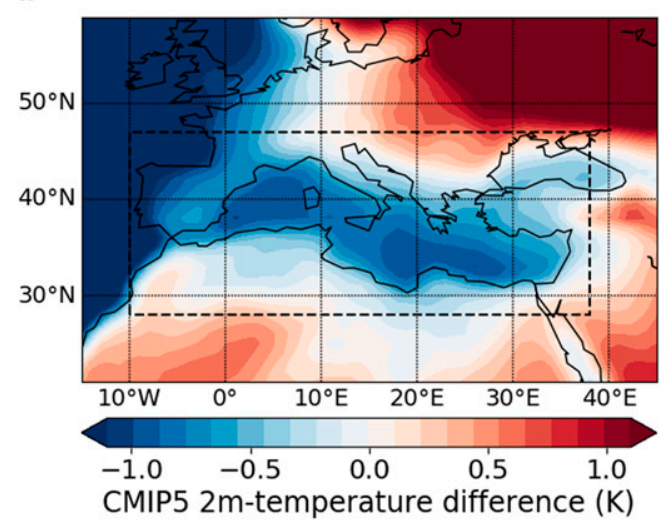

FIG. 6. (a) Difference in DJF mean 2-m temperature between the $0^{\circ} \mathrm{C}$ and $+1.5^{\circ} \mathrm{C}$ experiments (average of ERA and MPI simulations). (b) Change in DJF 2-m temperature under RCP8.5 (2071-2100 minus 1976-2005), from which the average Mediterranean land warming $(3.9 \mathrm{~K})$ was subtracted to highlight the relative cooling over the sea.

to assess the impact of a relative Mediterranean cooling in a climate change context as surrounding continents warm. Still, any GCM presents a number of biases in its background climate, which may modulate the impact of the relative cooling. The ERA experiments thus allow us to assess the circulation impact of a relative cooling in the current Mediterranean climate with no land warming.

Each set consists of a reference simulation (called " $0{ }^{\circ} \mathrm{C}$ ") and a perturbed simulation (called " $+1.5^{\circ} \mathrm{C}$ "), in which Mediterranean SSTs are artificially increased by $1.5^{\circ} \mathrm{C}$. The essence of the $+1.5^{\circ} \mathrm{C}$ simulations is to force the Mediterranean to warm as much as if it were land. We choose an SST difference of $1.5^{\circ} \mathrm{C}$ because it translates in the simulations into a $0.5^{\circ}-0.6^{\circ} \mathrm{C}$ change in the sea-land temperature index, consistent with the shift projected by CMIP5 models (Fig. 5; Fig. S4 in the online supplemental material). The difference between the reference and the perturbed simulations $\left(0^{\circ} \mathrm{C}\right.$ minus $+1.5^{\circ} \mathrm{C}$ ) corresponds to the impact of the relative Mediterranean cooling on regional circulation. The first set of simulations is referred to as "ERA" ("ERA0C" and "ERA $+1.5^{\circ} \mathrm{C}$ "), and the second set is referred to as "MPI" ("MPI0C" and "MPI $+1.5^{\circ} \mathrm{C}$ "). In all simulations, the first year is discarded as spinup. Long-term averages are computed over 1982-2011 for ERA experiments and 2071-2100 for MPI experiments.

\section{b. Results}

In comparison with the $+1.5^{\circ} \mathrm{C}$ experiments, the $0^{\circ} \mathrm{C}$ experiments exhibit a roughly $0.6^{\circ} \mathrm{C}$ relative cooling of the sea-land temperature index $\left(0.62^{\circ} \mathrm{C}\right.$ for ERA and $0.57^{\circ} \mathrm{C}$ for MPI; Fig. S4). The magnitude and spatial pattern of this relative cooling is similar to that projected by CMIP5 models (Fig. 6). Figure 7 shows the difference between the two experiments $\left(0^{\circ} \mathrm{C}\right.$ minus $\left.+1.5^{\circ} \mathrm{C}\right)$ in mean DJF SLP, 850-hPa wind, and precipitation fields over our simulation domain. As compared with the $+1.5^{\circ} \mathrm{C}$ simulations, the $0^{\circ} \mathrm{C}$ simulations exhibit a substantial anticyclonic flow in the boundary layer with a strong anomalous ridge generally located downstream of the SST anomaly. Both anticyclonic anomalies are accompanied by anomalous easterlies and northeasterlies over North Africa and the Middle East of about $0.5 \mathrm{~m} \mathrm{~s}^{-1}$ magnitude and a much weaker circulation response to the north. The pattern of the wind response south of $40^{\circ} \mathrm{N}$ is similar to that of the CMIP5 multimodel mean under RCP8.5, especially for the ERA experiments, even if of smaller magnitude (see Fig. 1c, noting that wind change is normalized by global temperature change, that is, divided by a factor $\approx 4$ ). The relative Mediterranean cooling is also associated with a pronounced regional precipitation decline. In absolute terms, this decline is strongest over the eastern half of the basin, particularly along the Turkish and Levant coastline. Precipitation is less affected west of $10^{\circ} \mathrm{E}$, except along the Algerian coastline.

The main difference between the ERA and MPI simulations is the location of the anomalous high. It is centered south of Greece and peaks at about $1.1 \mathrm{hPa}$ in ERA, whereas it is slightly weaker $(\approx 1 \mathrm{hPa})$ and shifted southeast in the MPI experiment (Figs. 7a,c). Averaging over the $0^{\circ}-30^{\circ} \mathrm{E}, 32^{\circ}-48^{\circ} \mathrm{N}$ domain, we find a $0.76-\mathrm{hPa}$ SLP difference between ERA0C and ERA $+1.5^{\circ} \mathrm{C}$ and $0.62-\mathrm{hPa}$ difference between MPI0C and MPI $+1.5^{\circ} \mathrm{C}$. Additionally, the baroclinicity of the response is much more pronounced in the MPI simulations. However, the background climates in the two reference $\left(0^{\circ} \mathrm{C}\right)$ 
a

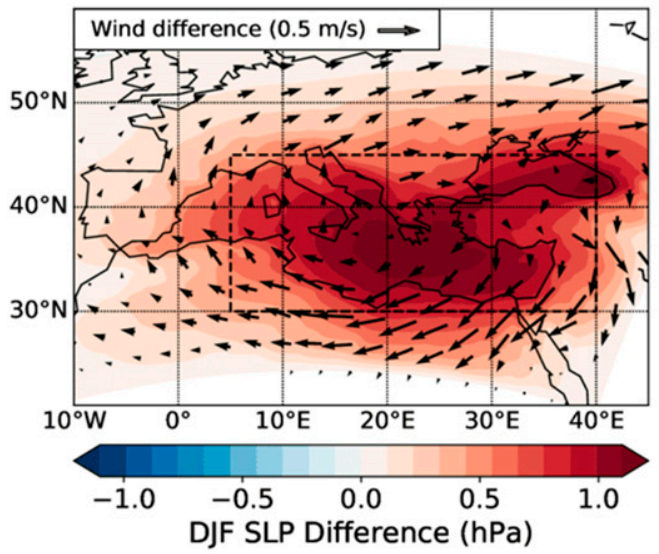

C

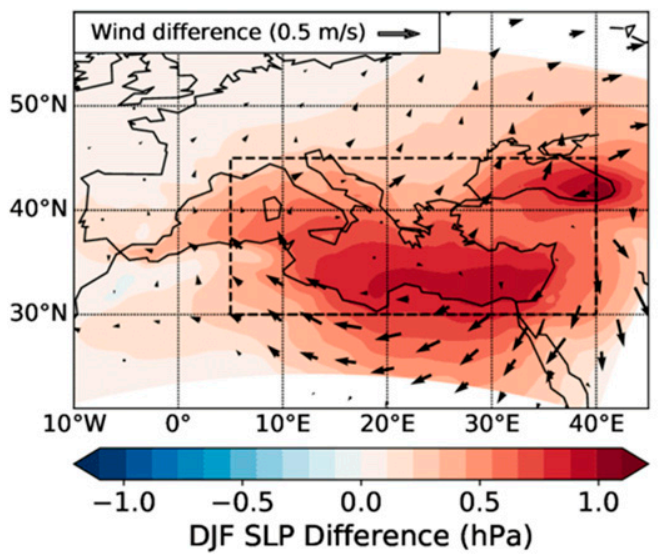

b

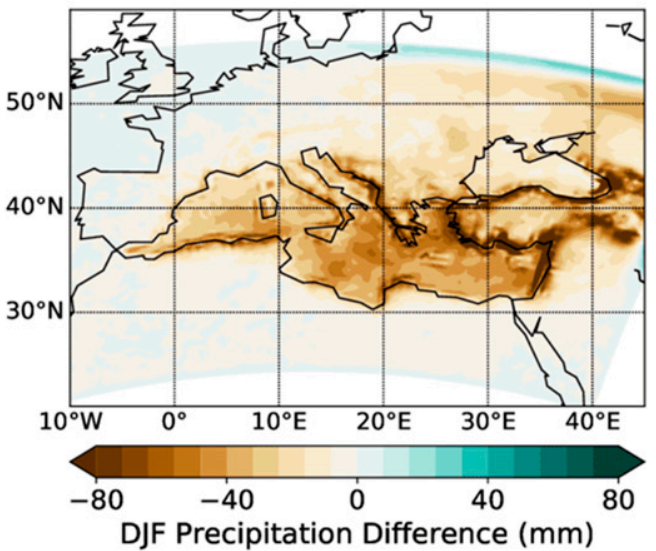

d

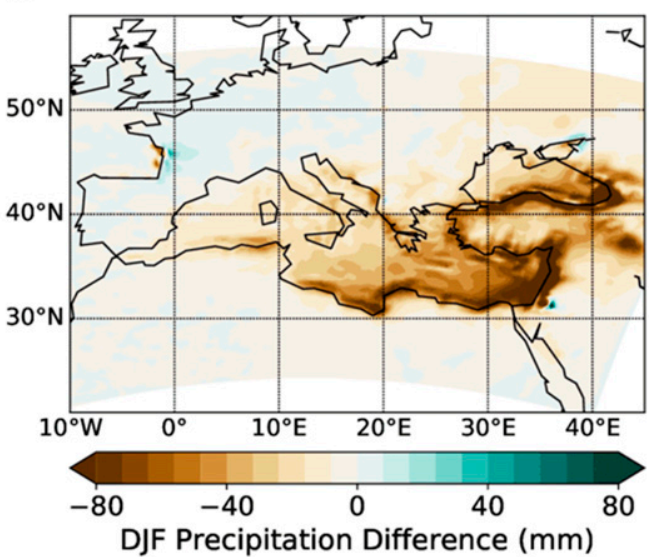

FIG. 7. Difference in DJF (left) SLP and 850 -hPa winds and (right) precipitation between the $+1.5^{\circ} \mathrm{C}$ and $0^{\circ} \mathrm{C}$ experiments $\left(0^{\circ} \mathrm{C}\right.$ minus $\left.1.5^{\circ} \mathrm{C}\right)$ in the (a),(b) ERA and (c),(d) MPI simulations.

simulations are different, notably the low-level zonal wind and static stability (Fig. S5 in the online supplemental material). Those two fields are critical in determining the atmospheric circulation response to shallow heating anomalies in the midlatitudes (Hoskins and Karoly 1981; Hall et al. 2001). The MPI reference state displays a slightly larger static stability over the Mediterranean and a stronger zonal wind field, both of which are consistent with a weaker circulation response to the imposed surface temperature anomaly in the MPI experiments. A larger static stability limits the expansion of the heating anomaly in the lower troposphere, while the enhanced zonal wind reduces the circulation response required to compensate for the heating anomaly (Hoskins and Karoly 1981). Furthermore, the MPI simulations also include long-term circulation trends induced by greenhouse gas forcing. Despite this, the circulation and precipitation responses to the relative cooling are very similar between ERA and MPI. This points toward a robust anticyclonic circulation response triggered by the relative Mediterranean cooling.

\section{Precipitation response}

The consequence of the development of the anomalous Mediterranean ridge is an increase in mass and moisture divergence by the mean flow, which drives a regional precipitation decline (Seager et al. 2014). However, the impacts are felt differently across the basin: the decrease in precipitation is most pronounced over southern Turkey to the east and over Morocco and the Iberian Peninsula to the west, away from the high pressure anomaly (Fig. 1).

The anomalous ridge is accompanied by a strong lowlevel wind field, that disrupts the relatively weak average circulation south of $40^{\circ} \mathrm{N}$. Thermal balance implies that subsidence will develop on the eastern margin of the Mediterranean ridge to compensate for cold advection from anomalous northerlies (Seager et al. 2014), which will tend to suppress precipitation. This view is consistent with the particularly large anomalous downward motion centered over that region in future projections (Fig. 8a). The time-mean regional energy balance can be written in pressure coordinates as (Rodwell and Hoskins 1996) 
a

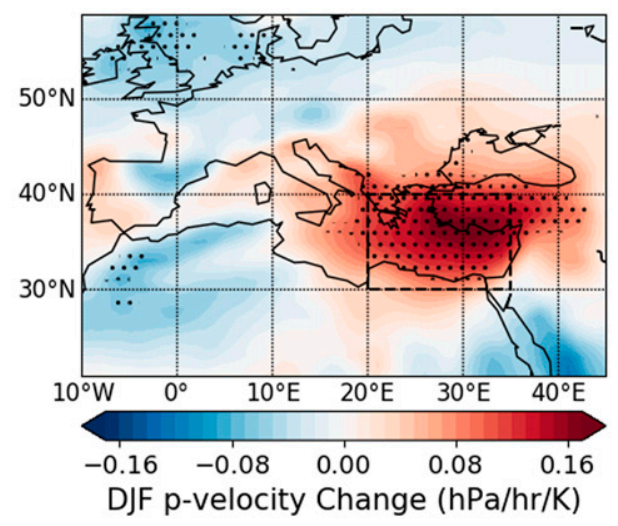

C

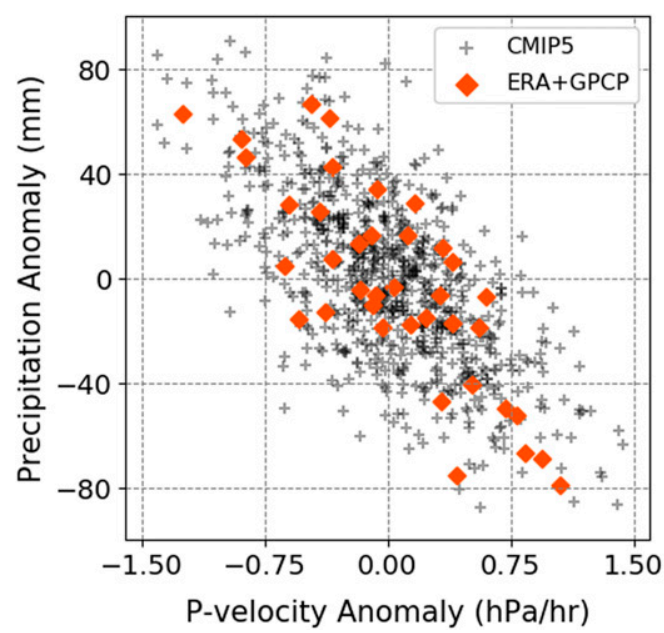

b

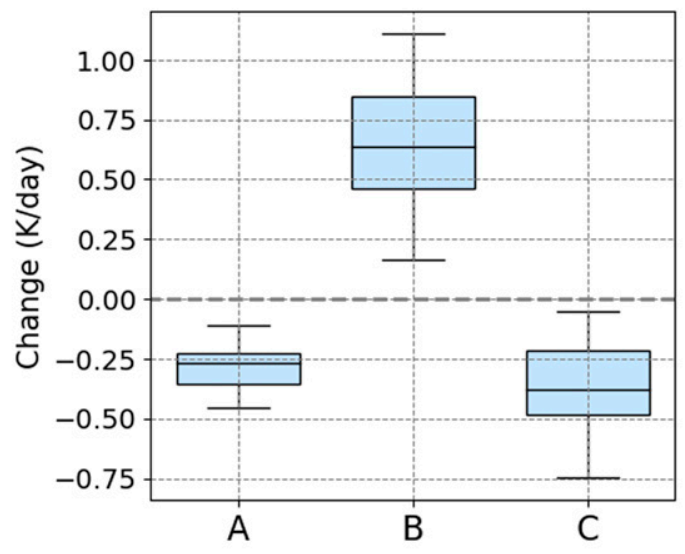

d

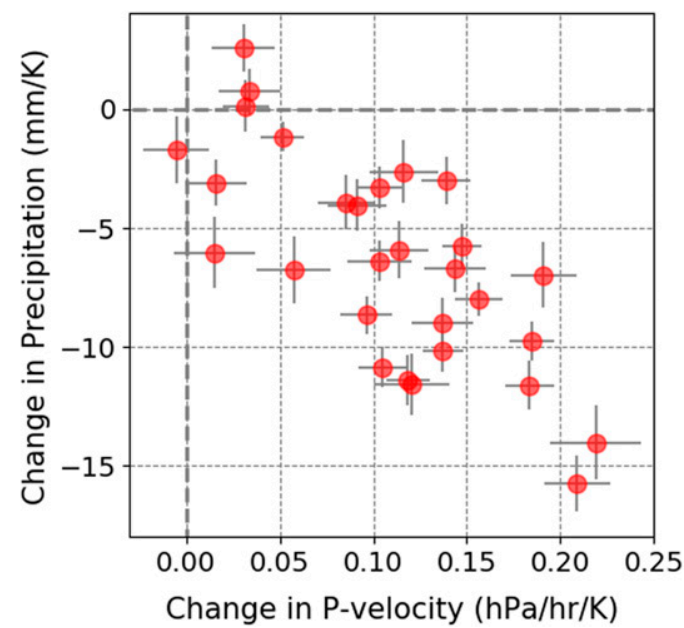

FIG. 8. (a) CMIP5 multimodel mean change in DJF 500-hPa pressure velocity, under the RCP8.5 scenario. For each model, projections were normalized by its mean annual global temperature change. Dots indicate that more than $80 \%$ of models agree on the sign of the change. (b) Change in column-integrated energy budget terms across CMIP5 models, averaged over the eastern Mediterranean [see dash-outlined box in (a)] [A: diabatic warming, B: vertical advection, and C: horizontal advection; see Eq. (2)]. (c) Eastern Mediterranean $\left[20^{\circ}-35^{\circ} \mathrm{E}, 30^{\circ}-40^{\circ} \mathrm{N}\right.$; see box in (a)] DJF precipitation and pressure velocity anomalies in historical (1976-2005) CMIP5 models and the observed record (1979-2018: ERA-Interim pressure velocity and GPCP precipitation). (d) Change in eastern Mediterranean DJF precipitation and pressure velocity across CMIP5 models, normalized by each model's mean annual global temperature change; $95 \%$ confidence intervals are shown by light-gray bars.

$$
\begin{aligned}
\frac{\overline{\partial T}}{\partial t}= & \underbrace{\frac{\bar{Q}}{c_{p}}}_{\mathrm{A}}-\underbrace{\left(\frac{p}{p_{0}}\right)^{\kappa} \bar{\omega} \frac{\partial \bar{\theta}}{\partial p}}_{\mathrm{B}}-\underbrace{\overline{\mathbf{u}} \cdot \nabla_{p} \bar{T}}_{\mathrm{C}}-\left(\frac{p}{p_{0}}\right)^{\kappa} \frac{\partial}{\partial p} \overline{\left(\omega^{\prime} \theta^{\prime}\right)} \\
& -\nabla_{p} \cdot \overline{\left(\mathbf{u}^{\prime} T^{\prime}\right),}
\end{aligned}
$$

where $t$ is time, $p$ is pressure, $T$ is temperature, $Q$ is diabatic heating/cooling, $c_{p}$ is the specific heat of dry air at constant pressure, $p_{0}$ is a reference pressure $(1000 \mathrm{hPa})$, $R$ is the specific gas constant for dry air, $\kappa=R / c_{p}, \omega$ is pressure velocity in pascals per second, $\theta$ is potential temperature, and $\mathbf{u}$ is the horizontal wind vector. Time means are denoted with overbars, and their deviations with '. Time means are computed in CMIP5 models for the 1976-2005 (reference) and 2071-2100 (future) periods. For long-term averages, the term on the left $(\overline{\partial T / \partial t})$ is about zero. The last two terms on the righthand side (transient terms) are also small (Fig. S6 in the online supplemental material), and the balance is between diabatic forcing (A), vertical advection (B), and horizontal advection (C). Those three terms also dominate changes in the long-term balance. Downward motion compensates for the cooling from anomalous northerlies; yet, because it also suppresses precipitation, 
a

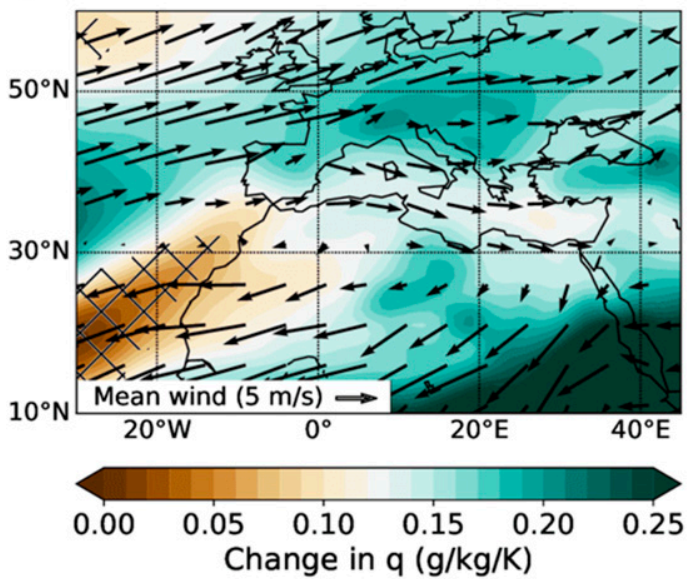

b

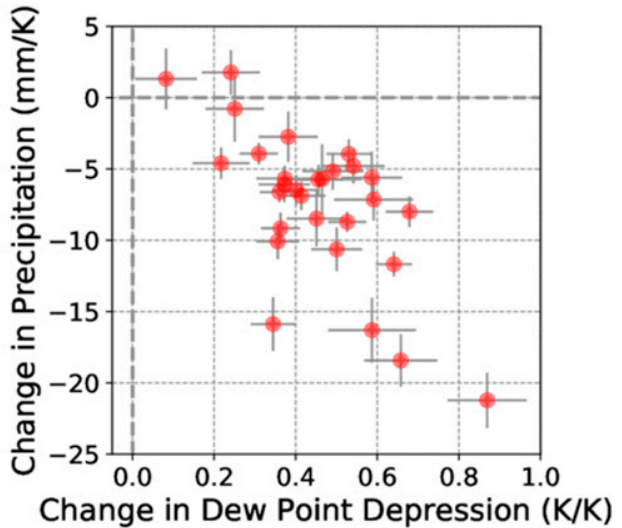

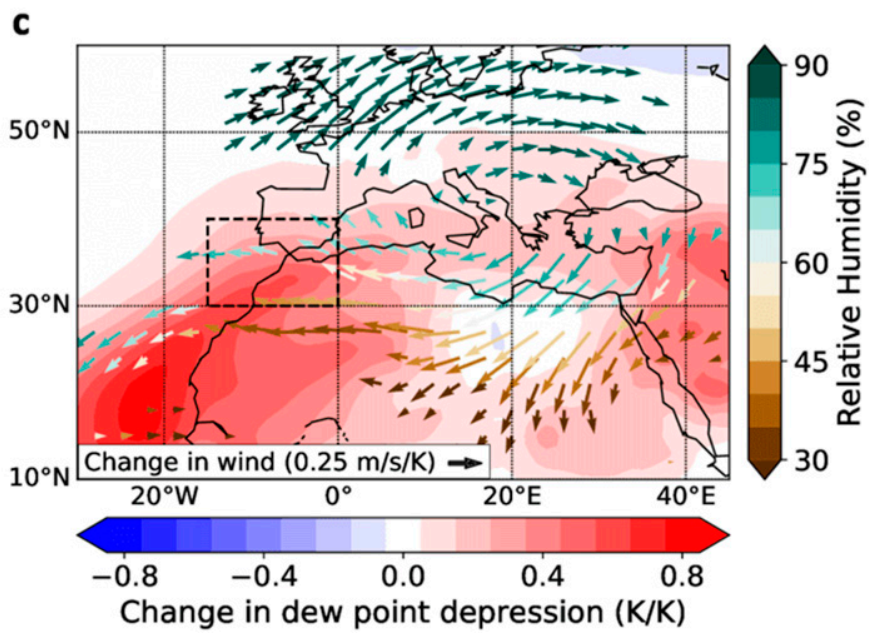

FIG. 9. CMIP5 multimodel mean change in DJF 925-850-hPa averaged (a) specific humidity and (c) dewpoint depression, normalized by each model's annual global-mean temperature change. Arrows indicate DJF historical [in (a)] and change in [in (c)] $925-850-\mathrm{hPa}$ averaged winds. Wind arrows in (c) are colored according to mean historical relative humidity at each point and are shown only where $80 \%$ of models agree on the sign of the change. (b) Western Mediterranean $\left[15^{\circ} \mathrm{W}-0^{\circ}, 30^{\circ}-40^{\circ} \mathrm{N}\right.$; dash-outlined box in (c)] DJF precipitation and dewpoint depression change across CMIP5 models, normalized by each model's mean annual global temperature change; $95 \%$ confidence intervals are shown by light-gray bars.

it indirectly leads to diabatic cooling of the air column (less vertical latent heat flux) and therefore reinforces itself. This likely explains why the cooling from horizontal advection is only about two-thirds of the change in adiabatic warming (Fig. 8b). Models correctly reproduce the interannual link between winter eastern Mediterranean $\backslash$ precipitation and vertical velocity anomalies (Fig. 8c). Across models, the change in seasonal precipitation is well correlated with that in pressure velocity (Fig. 8d).

To the west of the basin, this picture does not hold. There, while precipitation still declines, the trend is rather toward upward motion (Fig. 8a). Because anomalous winds associated with the low-level pressure high are predominantly easterly, they do not change the energy balance as much as they do over the eastern
Mediterranean. However, they have a substantial impact on the moisture budget. Atlantic westerlies are the direct source of precipitation for the western Mediterranean (Hurrell 1995). Projected circulation trends not only act to weaken this moisture influx, they also tend to advect much drier air from the Sahara Desert (Fig. 9c). Future projections show a consistent stagnation or weak increase in low-level specific humidity in the area (Fig. 9a). Combined with warming, this leads to a pronounced increase in dewpoint depression, well correlated with the regional precipitation decline across models (Fig. 9b).

In addition, as noted above, the relative cooling of Mediterranean SSTs may act to decrease precipitation not only through its effect on regional circulation but also 
by limiting the increase in evaporation and therefore moisture fluxes toward land. This might be an important factor for the eastern Mediterranean, which receives much of its winter precipitation from Mediterranean cyclones (Zappa et al. 2015a) (Figs. 7b,d).

While these elements seem to explain precipitation trends in GCMs, it is important to remember that both the eastern and western Mediterranean exhibit in reality complex orographic features, which play an important role in regional precipitation patterns. Their interaction with large-scale circulation trends may also impact future precipitation changes. Over southern Turkey, anomalous northerlies forced down the Anatolian plateau will cause subsidence and suppress precipitation. A similar phenomenon can be expected to occur north of the Atlas Range in Morocco and Algeria. These features are not well resolved by GCMs; already at our relatively coarse resolution $(35 \mathrm{~km})$ the orographic signal is much more detectable, and the enhanced precipitation decline south of Turkey may indicate further drying following subsidence induced by topography (Figs. 7b,d).

From this perspective, it is straightforward to understand the high correlation between the magnitude of anomalous SLP and Mediterranean-wide precipitation change (online supplemental Fig. S2). Even though the physical mechanisms behind the drying are different in the eastern and western Mediterranean, the change in SLP determines the strength of the anomalous circulation that drives the decline in precipitation at each end of the basin.

\section{Discussion}

\section{a. Uncertainties in the thermodynamical response}

The estimate of the SLP response to surface thermodynamical forcing is based on a roughly $0.5^{\circ} \mathrm{C}$ change in the land-sea temperature gradient, with limited variance across models. That change is in no small part determined by Mediterranean SST trends under continued greenhouse gas forcing, which in turn depend, among others, on Mediterranean Sea circulation. The latter, however, is not well resolved in GCMs (Planton et al. 2012). Reasons are to be found among the region's complex geography, its small size relative to model resolution and the very small extent $(15 \mathrm{~km})$ of the Gibraltar Strait, which plays a major role in the mass and energy balance of the Mediterranean (Sannino et al. 2002). Energy exchange with the Atlantic Ocean at Gibraltar must be parameterized in GCMs, which of course leaves room for substantial errors in long-term SST trends. In some models, the Mediterranean is even represented as a closed sea, which may tend to overestimate the SST response, with implications on the regional circulation change.
Despite obvious differences, the impact of the Mediterranean relative cooling on regional circulation and precipitation is relatively similar between the ERA and MPI experiments: a general increase in SLP of about $0.6 \mathrm{hPa}$, peaking over the eastern Mediterranean at around $1 \mathrm{hPa}$. This suggests that the response to relative cooling may also be similar when using other CMIP5 models as lateral boundary conditions.

\section{b. Combining mechanisms and other explanations}

Future Mediterranean circulation and hydroclimate trends in the CMIP5 multimodel mean appear to be primarily determined by large-scale circulation changes and regional thermodynamical forcing. Both mechanisms lead to higher pressure over the Mediterranean and can explain why the region is picked out as a prominent climate change hot spot. While other factors, like soil moisture feedback or stratospheric vortex strength (Zappa and Shepherd 2017; Simpson et al. 2018) can never be totally excluded, they seem unlikely to contribute much to the multimodel mean. In individual models, they may certainly play a large role, thus affecting intermodel spread.

The "dynamical" SLP response is higher over the western Mediterranean, which can be seen as an eastward shift of the North Atlantic subtropical high, consistent with the eastward shift of the stationary waves themselves (Simpson et al. 2016). Contrarily, the SLP anomaly due to relative Mediterranean cooling peaks downstream of the anomaly, that is, over the eastern Mediterranean. Although assessed within different modeling frameworks, our approach suggests that the two mechanisms may individually contribute somewhat equally to the Mediterranean SLP increase (about $+0.6-0.7 \mathrm{hPa}$, or $35 \%-40 \%$ of the mean projected response), and therefore to the precipitation decline. The dynamical SLP anomaly nevertheless clearly dominates in a number of models, in addition to being responsible for most of the intermodel spread. The strong geopotential ridge projected at upper levels above the Mediterranean by CMIP5 models (Seager et al. 2014) is also clearly associated with the planetary wave shift, not with the surface relative cooling, whose effect is limited to the lower troposphere (Fig. S7 in the online supplemental material).

A mutual reinforcement of the low-level anticyclonic circulation triggered by each forcing is, however, not to be excluded. Indeed, adding the SLP trends induced by our two mechanisms accounts for roughly $80 \%$ of the model-mean projected change, leaving a sizeable part unexplained. This unexplained fraction is even larger in several models. The discrepancy might result from nonlinear superposition (through self-reinforcement of 
the anomalies at low levels) or via the effects of surface friction, which also impacts the SLP response. In that regard, variability in regional orography and parameterization of friction may play an important role in explaining intermodel spread.

One other prominent feature of the midlatitude circulation change is an increase of SLP in the North Atlantic, between $45^{\circ} \mathrm{W}$ and $0^{\circ}$ (Fig. 1a). We find that part of this increase, along the $40^{\circ} \mathrm{N}$ parallel, where CMIP5 SLP trends are robust, may also be a response to upper-level circulation changes (Fig. 4a). North of there, the SLP change, though less robust, may be the downstream response to the NAWH, an area of relative SST cooling (Gervais et al. 2019), though this remains far from certain. Despite weaker intermodel agreement in this region during winter, a downstream increase in SLP extending to the Mediterranean is possible. Though it would not explain the robustness of the Mediterranean hot spot, it may combine with the robust anomalous positive SLP from our two proposed mechanisms. Model agreement in this region is stronger in spring and autumn, and this phenomenon could therefore also enhance the Mediterranean SLP response in those seasons, especially given the weaker projected upperlevel flow changes in early spring and late autumn (online supplemental Fig. S3). Simulation results of Gervais et al. (2019) suggest that the impact is small but not zero (their Figs. 3 and 5). They also used only one model. Analyzing, within a coherent modeling framework, the contributions of upper-level flow changes, the Mediterranean relative cooling, and the NAWH to future Mediterranean circulation trends may shed more light on this.

\section{c. Consistency of mechanisms with other studies}

We end by discussing the consistency of our results with those of previous studies. Among the various mechanisms proposed to explain the anomalous ridge, discussed in the introduction, we show in this paper that changes in stationary wave structure discussed by Simpson et al. (2016) play a crucial role, both for the model mean and intermodel spread (Fig. 4). Consequently, poleward shifts of the Hadley circulation and storm tracks, already shown to be limited in the Northern Hemisphere during winter, probably have limited direct influence. Recently, Brogli et al. (2019) concluded that large-scale circulation changes were the main driver the Mediterranean precipitation decline, and that regional effects were minimal. Their simulations that focus on the relative cooling of the Mediterranean also find a decrease in precipitation in the eastern Mediterranean compared to a scenario where SSTs warmed as much as the land (their Fig. 4). Yet, their conclusions were based on two models (MPI-ESM-LR and HadGEM2-ES) in which the contribution of uppertropospheric forcing happens to dominate (Fig. 4d). As we show here, however, large-scale dynamics have a wide range of effects across models; although they account for much of the spread in the precipitation response, large-scale circulation trends are not sufficient to fully explain regional projections.

In terms of precipitation response, our results agree with the perspective offered by Seager et al. (2014). In CMIP5 models, the Mediterranean drying is connected to changes in moisture convergence by the mean flow, but the drivers behind those changes vary from east to west. To the west, moisture convergence declines due to a weakening of the Atlantic moisture supply through increased advection of dry air from the Sahara. To the east, large-scale subsidence is the main cause of the precipitation decrease. In reality, however, precipitation is strongly linked to prominent topographic features that are, to a large extent, not resolved by GCMs. Orographic lifting and the interaction of mountains with large-scale circulation changes predicted by CMIP5 models will impact precipitation projections.

Our results also shed some light on the conclusions of Zappa et al. (2015a), who found the eastern Mediterranean precipitation decline to be associated with large reductions in cyclone frequency and intensity. We find that regional circulation and its changes control precipitation variability and change in the basin (online supplemental Fig. S2; Figs. 8 and 9) and therefore should control cyclonic activity, which is responsible for most of winter precipitation (Zappa et al. 2015a). The decrease in mean storm precipitation and dynamical weakening of cyclones they identified is consistent with the substantial anomalous regional downward motion over the region (Fig. 8a). In addition, anomalous northerlies advecting drier higher-latitude air and the relative Mediterranean cooling both act to constrain humidity trends, which likely cause the projected local minimum in specific humidity change near Cyprus (Fig. 9a). The weakening of the storm track is consistent with a weakening of the meridional temperature gradient between the Mediterranean Sea and the continent to its north, and the reduction in baroclinicity it may lead to. Future research should focus on understanding how the largescale drivers we identified control storm genesis in the Mediterranean.

\section{Conclusions}

In conclusion, our results offer a coherent and mechanistic picture of Mediterranean winter climate projections that is consistent with their robustness. It involves 
sound physical mechanisms and characteristics of the mean circulation: the shift in wavelengths of stationary waves, enhanced warming over land compared to oceans, and the baroclinic response to surface temperature anomalies. While much work remains to be done to understand the variability in SLP and precipitation change patterns across models, we find that the unique combination of the large-scale "dynamic" response and the independent, regional-scale "thermodynamic" response explain the robust regional maximization of wintertime climate change over the Mediterranean, making this region a major climate change hot spot for the coming decades. The contributions from each response appear comparable, though a nonlinear superposition may contribute to enhancing the response even more in certain models. Robust physical mechanisms involving local circulation account for the coherence of regional precipitation change and a maximized response at each end of the basin. Complex topography in those two regions indicates, however, that detailed regional simulations are required for improved future climate projections.

Acknowledgments. We acknowledge the World Climate Research Programme's Working Group on Coupled Modelling, which is responsible for CMIP, and we thank the climate modeling groups for producing and making available their model output. This work was made possible through funding from the Office Chérifien des Phosphates (OCP) through Université Mohamed VI Polytechnique, Morocco. The authors thank R. A. Plumb and P. O'Gorman for their remarks.

\section{REFERENCES}

Adler, R. F., and Coauthors, 2003: The Version-2 Global Precipitation Climatology Project (GPCP) monthly precipitation analysis (1979-present). J. Hydrometeor., 4, 1147-1167, https://doi.org/ 10.1175/1525-7541(2003)004<1147:TVGPCP $>2.0 . C O ; 2$.

Allan, R. J., and T. J. Ansell, 2006: A new globally complete monthly historical mean sea level pressure dataset (HadSLP2): 1850-2004. J. Climate, 19, 5816-5842, https://doi.org/10.1175/JCLI3937.1.

Barnes, E. A., and L. Polvani, 2013: Response of the midlatitude jets, and of their variability, to increased greenhouse gases in the CMIP5 models. J. Climate, 26, 7117-7135, https://doi.org/ 10.1175/JCLI-D-12-00536.1.

Bolle, H.-J., 2003: Climate, climate variability, and impacts in the Mediterranean area: An overview. Mediterranean Climate: Variability and Trends, H.-J. Bolle, Ed., Springer, 5-86, https:// doi.org/10.1007/978-3-642-55657-9_2.

Brandefelt, J., and H. Krnich, 2008: Northern Hemisphere stationary waves in future climate projections. J. Climate, 21, 6341-6353, https://doi.org/10.1175/2008JCLI2373.1.

Brogli, R., S. L. Sørland, N. Kröner, and C. Schär, 2019: Causes of future Mediterranean precipitation decline depend on the season. Environ. Res. Lett., 14, 114017, https://doi.org/10.1088/ 1748-9326/ab4438.
Byrne, M. P., and P. O'Gorman, 2016: Understanding decreases in land relative humidity with global warming: Conceptual model and GCM simulations. J. Climate, 29, 9045-9061, https://doi.org/10.1175/JCLI-D-16-0351.1.

_ and _ 2018: Trends in continental temperature and humidity directly linked to ocean warming. Proc. Natl. Acad. Sci. USA, 115, 4863-4868, https://doi.org/10.1073/pnas.1722312115.

Compo, G. P., and Coauthors, 2011: The Twentieth Century Reanalysis project. Quart. J. Roy. Meteor. Soc., 137, 1-28, https://doi.org/10.1002/qj.776.

Dee, D. P., and Coauthors, 2011: The ERA-Interim reanalysis: Configuration and performance of the data assimilation system. Quart. J. Roy. Meteor. Soc., 137, 553-597, https://doi.org/ 10.1002/qj.828.

Deser, C., L. Terray, and A. S. Phillips, 2016: Forced and internal components of winter air temperature trends over North America during the past 50 years: Mechanisms and implications. J. Climate, 29, 2237-2258, https://doi.org/10.1175/JCLI-D-15-0304.1.

Gervais, M., J. Shaman, and Y. Kushnir, 2019: Impacts of the North Atlantic warming hole in future climate projections: Mean atmospheric circulation and the North Atlantic jet. J. Climate, 32, 2673-2689, https://doi.org/10.1175/JCLI-D-18-0647.1.

Gianotti, R. L., and E. A. B. Eltahir, 2014a: Regional climate modeling over the Maritime Continent. Part I: New parameterization for convective cloud fraction. J. Climate, 27, 1488-1503, https://doi.org/10.1175/JCLI-D-13-00127.1.

$\longrightarrow$, and — 2014b: Regional climate modeling over the Maritime Continent. Part II: New parameterization for autoconversion of convective rainfall. J. Climate, 27, 1504-1523, https://doi.org/10.1175/JCLI-D-13-00171.1.

_ D. Zhang, and E. A. B. Eltahir, 2012: Assessment of the Regional Climate Model version 3 over the Maritime Continent using different cumulus parameterization and land surface schemes. J. Climate, 25, 638-656, https://doi.org/10.1175/JCLI-D-11-00025.1.

Giorgi, F., and X. Bi, 2005: Updated regional precipitation and temperature changes for the 21st century from ensembles of recent AOGCM simulations. Geophys. Res. Lett., 32, L21715, https://doi.org/10.1029/2005GL024288.

— , and P. Lionello, 2008: Climate change projections for the Mediterranean region. Global Planet. Change, 63, 90-104, https://doi.org/10.1016/j.gloplacha.2007.09.005.

Hall, N. M., H. Lin, and J. Derome, 2001: The extratropical signal generated by a midlatitude SST anomaly. Part II: Influence on seasonal forecasts. J. Climate, 14, 2696-2709, https://doi.org/ 10.1175/1520-0442(2001)014<2696:TESGBA > 2.0.CO;2.

Harris, I., P. D. Jones, T. J. Osborn, and D. H. Lister, 2014: Updated high-resolution grids of monthly climatic observations-The CRU TS3.10 Dataset. Int. J. Climatol., 34, 623-642, https:// doi.org/10.1002/joc.3711.

He, J., and B. J. Soden, 2017: A re-examination of the projected subtropical precipitation decline. Nat. Climate Change, $\mathbf{7}$, 53-57, https://doi.org/10.1038/nclimate3157.

Held, I. M., M. Ting, and H. Wang, 2002: Northern winter stationary waves: Theory and modeling. J. Climate, 15, 2125-2144, https:// doi.org/10.1175/1520-0442(2002)015<2125:NWSWTA $>2.0 . C O ; 2$.

Hoerling, M., J. Eischeid, J. Perlwitz, X. Quan, T. Zhang, and P. Pegion, 2012: On the increased frequency of Mediterranean drought. J. Climate, 25, 2146-2161, https://doi.org/10.1175/ JCLI-D-11-00296.1.

Hoskins, B. J., and D. J. Karoly, 1981: The steady linear response of a spherical atmosphere to thermal and orographic forcing. J. Atmos. Sci., 38, 1179-1196, https://doi.org/10.1175/ 1520-0469(1981)038<1179:TSLROA > 2.0.CO;2. 
Huang, B., and Coauthors, 2017: Extended Reconstructed Sea Surface Temperature, version 5 (ERSSTv5): Upgrades, validations, and intercomparisons. J. Climate, 30, 8179-8205, https://doi.org/10.1175/JCLI-D-16-0836.1.

Hurrell, J. W., 1995: Decadal trends in the North Atlantic oscillation: Regional temperatures and precipitation. Science, 269, 676-679, https://doi.org/10.1126/science.269.5224.676.

Im, E.-S., and E. A. B. Eltahir, 2018a: Simulation of the diurnal variation of rainfall over the western Maritime Continent using a regional climate model. Climate Dyn., 51, 73-88, https://doi.org/10.1007/s00382-017-3907-3.

_ and _ 2018b: Simulations of the observed 'jump' in the West African monsoon and its underlying dynamics using the MIT regional climate model. Int. J. Climatol., 38, 841-852, https://doi.org/10.1002/joc.5214.

Kalnay, E., and Coauthors, 1996: The NCEP/NCAR 40-Year Reanalysis Project. Bull. Amer. Meteor. Soc., 77, 437-472, https:// doi.org/10.1175/1520-0477(1996)077<0437:TNYRP>2.0.CO;2.

Kelley, C., M. Ting, R. Seager, and Y. Kushnir, 2012: The relative contributions of radiative forcing and internal climate variability to the late 20th century winter drying of the Mediterranean region. Climate Dyn., 38, 2001-2015, https://doi.org/10.1007/ s00382-011-1221-z.

_ S. Mohtadi, M. A. Cane, R. Seager, and Y. Kushnir, 2015: Climate change in the Fertile Crescent and implications of the recent Syrian drought. Proc. Natl. Acad. Sci. USA, 112, 32413246, https://doi.org/10.1073/pnas.1421533112.

Lu, J., G. A. Vecchi, and T. Reichler, 2007: Expansion of the Hadley cell under global warming. Geophys. Res. Lett., 34, L06805, https://doi.org/10.1029/2006GL028443.

Pal, J. S., and E. A. B. Eltahir, 2016: Future temperature in southwest Asia projected to exceed a threshold for human adaptability. Nat. Climate Change, 6, 197-200, https://doi.org/10.1038/nclimate2833.

_ and Coauthors, 2007: Regional climate modeling for the developing world: The ICTP RegCM3 and RegCNET. Bull. Amer. Meteor. Soc., 88, 1395-1410, https://doi.org/10.1175/BAMS-88-9-1395.

Planton, S., and Coauthors, 2012: The climate of the Mediterranean region in future climate projections. The Climate of the Mediterranean Region, P. Lionello, Ed., Elsevier, 449-502, https://doi.org/10.1016/B978-0-12-416042-2.00008-2.

Poli, P., and Coauthors, 2016: ERA-20C: An atmospheric reanalysis of the twentieth century. J. Climate, 29, 4083-4097, https://doi.org/10.1175/JCLI-D-15-0556.1.

Rayner, N. A., D. E. Parker, E. B. Horton, C. K. Folland, L. V. Alexander, D. P. Rowell, E. C. Kent, and A. Kaplan, 2003: Global analyses of sea surface temperature, sea ice, and night marine air temperature since the late nineteenth century. J. Geophys. Res., 108, 4407, https://doi.org/10.1029/2002JD002670.

Reynolds, R. W., T. M. Smith, C. Liu, D. B. Chelton, K. S. Casey, and M. G. Schlax, 2007: Daily high-resolution blended analyses for sea surface temperature. J. Climate, 20, 5473-5496, https://doi.org/10.1175/2007JCLI1824.1.

Rodwell, M. J., and B. J. Hoskins, 1996: Monsoons and the dynamics of deserts. Quart. J. Roy. Meteor. Soc., 122, 1385-1404, https://doi.org/10.1002/qj.49712253408.

Rojas, M., L. Z. Li, M. Kanakidou, N. Hatzianastassiou, G. Seze, and H. L. Treut, 2013: Winter weather regimes over the Mediterranean region: Their role for the regional climate and projected changes in the twenty-first century. Climate Dyn., 41, 551-571, https://doi.org/10.1007/s00382-013-1823-8.

Sannino, G., A. Bargagli, and V. Artale, 2002: Numerical modeling of the mean exchange through the Strait of Gibraltar. J. Geophys. Res., 107, 3094, https://doi.org/10.1029/2001JC000929.
Scheff, J., and D. Frierson, 2012: Twenty-first-century multimodel subtropical precipitation declines are mostly midlatitude shifts. J. Climate, 25, 4330-4347, https://doi.org/10.1175/ JCLI-D-11-00393.1.

Seager, R., H. Liu, N. Henderson, I. R. Simpson, C. Kelley, T. Shaw, Y. Kushnir, and M. Ting, 2014: Causes of increasing aridification of the Mediterranean region in response to rising greenhouse gases. J. Climate, 27, 4655-4676, https://doi.org/ 10.1175/JCLI-D-13-00446.1.

— T. Tsborn, Y. Kushnir, I. Simpson, J. Nakamura, and H. Liu, 2019: Climate variability and change of Mediterranean-type climates. J. Climate, 32, 2887-2915, https://doi.org/10.1175/ JCLI-D-18-0472.1.

Simpson, I. R., R. Seager, M. Ting, and T. A. Shaw, 2016: Causes of change in Northern Hemisphere winter meridional winds and regional hydroclimate. Nat. Climate Change, 6, 65-70, https:// doi.org/10.1038/nclimate2783.

—, P. Hitchcock, R. Seager, Y. Wu, and P. Callaghan, 2018: The downward influence of uncertainty in the Northern Hemisphere stratospheric polar vortex response to climate change. J. Climate, 31, 6371-6391, https://doi.org/10.1175/ JCLI-D-18-0041.1.

Sutton, R. T., B. Dong, and J. M. Gregory, 2007: Land/sea warming ratio in response to climate change: IPCC AR4 model results and comparison with observations. Geophys. Res. Lett., 34, L02701, https://doi.org/10.1029/2006GL028164.

Taylor, K. E., R. J. Stouffer, and G. A. Meehl, 2012: An overview of CMIP5 and the experiment design. Bull. Amer. Meteor. Soc., 93, 485-498, https://doi.org/10.1175/BAMS-D-11-00094.1.

Tuel, A., and E. A. B. Eltahir, 2018: Large-scale circulation and precipitation decline in the Mediterranean. 2018 Fall Meeting, Washington, DC, Amer. Geophys. Union, Abstract A41F-08.

Vose, R., and Coauthors, 2012: NOAA's Merged Land-Ocean Surface Temperature analysis. Bull. Amer. Meteor. Soc., 93, 1677-1685, https://doi.org/10.1175/BAMS-D-11-00241.1.

Winter, J. M., J. S. Pal, and E. A. B. Eltahir, 2009: Coupling of integrated biosphere simulator to Regional Climate Model version 3. J. Climate, 22, 2743-2757, https://doi.org/10.1175/ 2008JCLI2541.1.

Woollings, T., J. M. Gregory, J. G. Pinto, M. Reyers, and D. J. Brayshaw, 2012: Response of the North Atlantic storm track to climate change shaped by ocean-atmosphere coupling. Nat. Geosci., 5, 313-317, https://doi.org/10.1038/ngeo1438.

Yin, J. H., 2005: A consistent poleward shift of the storm tracks in simulations of 21st century climate. Geophys. Res. Lett., 32, L18701, https://doi.org/10.1029/2005GL023684.

Zanchettin, D., A. Rubino, D. Matei, O. Bothe, and J. Jungclaus, 2013: Multidecadal-to-centennial SST variability in the MPIESM simulation ensemble for the last millennium. Climate Dyn., 40, 1301-1318, https://doi.org/10.1007/s00382-012-1361-9.

Zappa, G., and T. G. Shepherd, 2017: Storylines of atmospheric circulation change for European regional climate impact assessment. J. Climate, 30, 6561-6577, https://doi.org/10.1175/ JCLI-D-16-0807.1.

_ M. K. Hawcroft, L. Shaffrey, E. Black, and D. J. Brayshaw, 2015a: Extratropical cyclones and the projected decline of winter Mediterranean precipitation in the CMIP5 models. Climate Dyn., 45, 1727-1738, https://doi.org/10.1007/ s00382-014-2426-8.

— B. J. Hoskins, and T. G. Shepherd, 2015b: The dependence of wintertime Mediterranean precipitation on the atmospheric circulation response to climate change. Environ. Res. Lett., 10, 104012, https://doi.org/10.1088/1748-9326/10/10/104012. 